\section{Reduced increments in plasma renin activity and catecholamines during exercise in Type 1 (insulin-dependent) diabetic patients}

Dear Sir,

We read with interest the paper of Sundkvist et al. [1]. The authors conclude that Type 1 (insulin-dependent) diabetic patients demonstrated reduced increments in plasma renin activity and catecholamines during exercise.

The impaired catecholamine response was confined to patients with autonomic neuropathy. We have recently completed studies comparing the response to exercise of a group of uncomplicated Type 1 diabetic patients and normal subjects [2]. Resting noradrenaline levels were reduced but there was an enhanced response to exercise (unpublished data). Another study showed reduced resting plasma noradrenaline levels in young Type 1 diabetic patients and a normal exercise response [3].

The authors' claim of an abnormal noradrenaline response to exercise in patients with cardiac autonomic neuropathy is of interest but we do not believe the patients were adequately defined. Cardiac autonomic neuropathy was defined as one abnormal result for the expiration/inspiration ratio, acceleration index or brake index. While the expiration/inspiration ratio is in common use as a test of autonomic function, most workers advocate measurement of the Valsalva ratio and heart rate response to standing [4] which were not performed in this study. Furthermore, a diagnosis of cardiac autonomic neuropathy requires at least two clearly abnormal results. Lesser degrees of abnormality are reversible and not diagnostic: three out of nine diabetic subjects who took part in a study of impotence [5] showed reversal of this abnormality within two years (D. A. Cavan, unpublished data). The authors may therefore have over-estimated the frequency of autonomic neuropathy: indeed they found reversibility of abnormal results in 4 out of 23 subjects but it is not clear into which group these were classified.

We have shown a similar plasma renin activity response to exercise in uncomplicated Type 1 diabetic subjects and age and sexmatched control subjects. The data of Sundkvist et al. is at variance with our findings. This may be a consequence of either inadequate matching of their groups or the presence of complications in the diabetic group. The diabetic group was significantly older than the control group $(p<0.01)$. Increased age is associated with reduced plasma renin activity [6]. While resting plasma renin activity was similar in the diabetic and control groups, the impaired plasma renin activity response may reflect merely the greater age of the diabetic subjects.

Ten subjects had retinopathy and five macroalbuminuria but there is no information on the frequency of microalbuminuria which itself is associated with altered plasma renin activity [7]. Plasma renin activity may also be suppressed by poor glycaemic control [8] but no information on this is given. Only with information on the glycaemic control and complications of the diabetic subjects can the data on plasma renin activity be interpreted.

Yours faithfully,

D. A. Cavan, M.J.O'Donnell and A.H. Barnett

\section{References}

1. Sundkvist $G$, Bergström B, Bramnert M, Lilja B, Manhem $P$ (1990) The activity of the renin-angiotensin-aldosterone system before and during submaximal bicycle exercise in relation to circulatory catecholamines in patients with Type 1 (insulin-dependent) diabetes mellitus. Diabetologia 33: 148-151

2. Cavan DA, O'Donnell MJ, Lewis H, Lawson N, Parkes A, Barnett $\mathrm{AH}$ (in press) Blood pressure, plasma renin activity and atrial peptide response to exercise in normoalbuminuric Type 1 diabetic patients. Diabetic Med

3. Johanssen BL, Berg V, Bohlin AB, Lefvert AK, Freyschuss V (1987) Exercise induced changes in renal function and their relation to plasma noradrenaline in insulin-dependent diabetic children and adolescents. Clin Sci 72:611-620

4. Ewing DJ, Clarke BF (1986) Autonomic neuropathy: its diagnosis and prognosis. Clin Endocrinol Metab 15: 855-888

5. Cavan DA, Barnett AH, Leatherdale BA (1987) Diabetic impotence: Risk factors in a clinic population. Diabetes Res 5: 145148

6. Noth RH, Lassman MN, Tan SY, Fernandez-Cruz A, Mulrow PJ (1977) Age and the renin-aldosterone system. Arch Intern Med 137: 1414-1417

7. O'Donnell MJ, Lawson N, Barnett AH (1989) Activity of the unstimulated Renin-Angiotensin-Aldosterone system in type 1 diabetic patients with and without proteinuria. Diabetic Med 6: $422-425$

8. Bell GM, Bernstein RK, Laragh JH, et al. (1989) Increased plasma atrial natriuretic factor and reduced plasma renin in patients with poorly controlled diabetes mellitus. Clin Sci 77: 177-182

D.A. Cavan

East Birmingham Health Authority

East Birmingham Hospital

Bordesley Green East

Birmingham B9 5ST

UK

\section{Response from the authors}

Dear Sir,

The questions raised by Cavan et al. gives us the opportunity to further discuss our findings [1]. The methods employed in the evaluation of autonomic nerve function are well established. In the original report 10 years ago [2] we showed that the acceleration and brake indices, computed from the immediate heart rate reaction to tilt, have clear advantages compared with a test of autonomic neuropathy based on the heart rate reaction to standing up. A procedure in which the patient is tilted to the upright position is easier to standardize and more reliable than a test in which the patient is asked to stand up. Moreover, it has been shown that the acceleration and brake indices provide valuable information regarding the relationships between signs and symptoms of autonomic neuropathy [3], prognosis of autonomic neuropathy [4], the putative risk for developing nephropathy [5], and in the establishment of sympathetic nerve involvement in autonomic neuropathy [6-7]. The potency of the tests to detect autonomic neuropathy was verified by the present 
study. The observation that low catecholamine increments to exercise were confined to patients with signs of cardiac autonomic neuropathy proves that employed tests adequately identified autonomic neuropathy. The observation that patients with normal cardiac autonomic neuropathy tests showed normal catecholamine increments to exercise fits well with the observation of Cavan et al. that young and uncomplicated Type 1 (insulin-dependent) diabetic patients have normal to increased increments in noradrenaline to exercise.

Cavan et al. suggested that the reduced renin response to exercise in Type 1 diabetic patients was related to an inadequate agematching and/or the occurrence of diabetic complications. However, it is unlikely that age, nephropathy, and retinopathy were of major importance for the impaired renin response. The patient material has been re-evaluated. In keeping with the results in the whole patient material, a selected strictly aged-matched patient sub-group (14 patients aged 19 to 36 years; mean $30 \pm 1$ years) also showed low increments in renin activity during exercise $\left(2.0 \pm 0.5 \mathrm{nmol} \cdot \mathrm{l}^{-1} \cdot \mathrm{h}^{-1}\right.$ vs $\left.3.7 \pm 0.5 \mathrm{nmol} \cdot 1^{-1} \cdot \mathrm{h}^{-1} ; p<0.05\right)$ compared with control subjects. An influence of diabetes duration is unlikely since there were no significant correlations between the duration of diabetes and renin values. Moreover, 11 patients without albuminuria (albumin in urine $<0.02 \mathrm{~g} / \mathrm{l}$ ) showed as low renin at $80 \%$ of maximal exercise as the 12 patients with nephropathy $\left(2.4 \pm 0.7 \mathrm{nmol} \cdot 1^{-1} \cdot \mathrm{h}^{-1}\right.$ vs $2.7 \pm 0.5 \mathrm{nmol} \cdot \mathrm{1}^{-1} \cdot \mathrm{h}^{-1}$; NS) clearly indicating that diabetic patients without nephropathy also had significantly $(p<0.05)$ lower renin values at $80 \%$ of maximal exercise compared with the control subjects. Regarding retinopathy, there was a tendency though not significant for patients with retinopathy $(n=9)$ to show lower renin values at $80 \%$ of maximal exercise $\left(2.0 \pm 0.3 \mathrm{nmol} \cdot 1^{-1} \cdot \mathrm{h}^{-1}\right.$ vs $3.0 \pm 0.7 \cdot 1^{-1} \cdot h^{-1}$; NS) than patients without. However, patients both with and without retinopathy showed lower renin values at $80 \%$ of maximal exercise than control subjects $(p<0.01$ and $p<0.05$, respectively). The influence of diabetic control was difficult to assess. As expected, blood glucose values were higher in patients than in control subjects but the metabolic control was not particularly bad; postprandial blood glucose prior to exercise was $9.8 \pm 0.8 \mathrm{mmol} / \mathrm{lin}$ the patients.

In conclusion, Type 1 diabetic patients demonstrated lower increments in renin during exercise than control subjects and the deviation was unrelated to the presence of cardiac autonomic neuropathy, disturbances in circulatory catecholamines, nephropathy, retinopathy, age, and the duration of diabetes. Whether the disturbed renin response is related to hyperglycaemia or is an intrinsic feature of Type 1 diabetes has to be elucidated.

Yours sincerely,

G. Sundkvist on behalf of my coauthors

\section{References}

1. Sundkvist G, Bergström B, Bramnert M, Lilja B, Manhem P (1990) The activity of the renin-angiotensin-aldosterone system before and during submaximal bicycle exercise in relation to circulatory catecholamines in patients with Type 1 (insulin-dependent) diabetes mellitus. Diabetologia 33: 148-151

2. Sundkvist G, Lilja B, Almér L-O (1980) Abnormal diastolic blood pressure and heart rate reactions to tilting in diabetes mellitus. Diabetologia 19: 433-438

3. Sundkvist G (1981) Autonomic nervous function in asymptomatic diabetic patients with signs of peripheral neuropathy. Diabetes Care 4: 529-534

4. Sundkvist G, Lilja B (1985) Autonomic neuropathy in diabetes mellitus. A follow up study. Diabetes Care 8: 129-133

5. Lilja B, Nosslin B, Bergström B, Sundkvist G (1985) Glomerular filtration rate, autonomic nerve function, and ortho-static blood pressure in patients with diabetes mellitus. Diabetes Res 2: 179 181

6. Sundkvist G, Lilja B, Manhem P, Almér L-O (1984) Responses of plasma catecholamines to tilt in patients with diabetes mellitus. Acta Med Scand 216: 223-227
7. Bergström B, Manhem P, Bramnert M, Lilja B, Sundkvist G (1989) Impaired responses of plasma catecholamines to exercise in diabetic patients with abnormal heart rate reactions to tilt. Clin Physiol 9: 259-267

\section{G. Sundkvist}

Department of Medicine

University of Lund

Malmö General Hospital

S-21401 Malmö

Sweden

\section{Evidence for lactate production by human adipose tissue in vivo}

\section{Dear Sir,}

We are pleased that measurements of interstitial fluid lactate in human adipose tissue [1] confirm our finding [2], based on arteriovenous differences, that adipose tissue is a net producer of lactate in vivo. However, we find some of the comments made by Dr. Jansson and colleagues rather misleading. They describe our preparation as one of 'skin and an unknown amount of the abdominal fat'. Since both groups are studying the same adipose depot, the metabolic contribution of skin seems likely to be similar in the two preparations. We have summarised evidence that this contribution is, in fact, small [2]. Jansson et al. discuss an 'apparent difference in lactate concentration between the interstitial water and the epigastric vein'. The concentrations reported in our paper were of lactate in whole blood. Since human plasma lactate concentrations are about $40 \%$ higher than those in whole blood [3], the results are actually in very good agreement. Finally, our work is apparently criticised for lack of measurement of blood flow, although the same applies, of course, to the microdialysis measurements. We have now added the measurement of adipose tissue blood flow to our studies, and have thus been able to quantitate substrate exchanges in human adipose tissue after ingestion of a meal [4]. It is perhaps worth pointing out that a complete study of this sort requires measurement of lipoprotein triacylglycerol exchange, unfortunately not yet possible by the microdialysis technique.

Yours sincerely,

K. N. Frayn and S. W. Coppack

\section{References}

1. Jansson P-A, Smith U, Lönnroth P (1990) Evidence for lactate production by human adipose tissue in vivo. Diabetologia $33: 253$ 256

2. Frayn KN, Coppack SW, Humphreys SM, Whyte PL (1989) Metabolic characteristics of human adipose tissue in vivo. Clin Sci 76 : 509-516

3. Foster KJ, Alberti KGMM, Hinks L, Lloyd B, Postle A, Smythe P, Turnell DC, Walton R (1978) Blood intermediary metabolite and insulin concentrations after an overnight fast: reference ranges for adults, and interrelations. Clin Chem 24: 1568-1572

4. Coppack SW, Fisher RM, Gibbons GF, Humphreys SM, McDonough MJ, Potts JL, Frayn KN (1990) Postprandial substrate deposition in human forearm and adipose tissues in vivo. Clin Sci 79: $339-348$

Drs. K. N. Frayn and S. W. Coppack

Sheikh Rashid Diabetes Unit

Radcliffe Infirmary

Oxford OX2 6HE

UK 